\title{
Effects of Automation on Construction Industry Performance
}

\author{
Ayodeji Oke $^{1, a}$, Clinton Aigbavboa ${ }^{1, b}$, Siphiwe Mabena ${ }^{1, c}$ \\ ${ }^{1}$ Department of Construction Management and Quantity Surveying, University of Johannesburg, \\ Doornfontein, 2028, South Africa \\ aemayok@gmail.com, ${ }^{b}$ caigbavboa@uj.ac.za, ${ }^{\mathrm{c} m a b e n a . s 12 @ g m a i l . c o m ~}$
}

\section{Keywords: Automation, Construction industry, Project performance}

\begin{abstract}
The growth of infrastructure and development in an emerging country like South Africa may requires the construction industry to shift from traditional methods of construction to modern ones in order to improve productivity and enhance performance. However, most of the existing studies have been tailored towards the awareness, willingness, drivers, barriers and benefits of such modern methods, including automation and robotics. Like other technological advancement, there are some negative impacts that should be assessed and understood by stakeholders with a view to managing and minimizing them. In view of this, the purpose of this study is to investigate the extent to which the usage of automation can influence negatively on the delivery of construction projects if fully implemented in the South African construction industry.
\end{abstract}

\section{Introduction}

With the increase in urbanization, more people are continuously moving from the villages and other rural areas to the city and therefore the infrastructure needs to be re-evaluated in order to accommodate the influx. South Africa's construction industry has transformed significantly over the last 20 years and there has been market expansion since the apartheid period when it was constrained by sanctions and racial policies which was restricting its growth [1]. There has been a call for the adoption of modern technologies in order to meet the growing demand of the populace [2], and one of the current method been advocated by construction stakeholders is the use of automation and robotics for construction activities. To promote the usage and adoption of automation in the industry, several studies have been carried out with more interest in the means of adoption and potential benefits where it has not been fully utilized [3-5]. Further to the existing studies, this research was construed to examine the negative influences of construction automation in the South African construction industry with a view to create awareness among stakeholders and suggest possible ways of managing and controlling the effects.

\section{Automation in Construction}

For a better understanding of the concept of robotics and automation and their relevance to the construction industry, there is a need for detailed explanation of the terms. However, the concepts were described from general perspective before relating them to construction performance and the construction industry.

Automation can be defined as a self-regulating procedure done by utilizing computerized machines to carry out various tasks [6]. Furthermore, automated machines can work in accordance with a program that regulated the behavior of the machine. During the early twentieth century, soon after the improvement of electrical devices and time-switches, more techniques turned out to be consequently controlled, and various essential businesses such as food processing and oil-refining were turning out to be progressively computerized [3]. After World War 2, the development of computers allowed more complicated automated machines to be used in manufacturing industries; the assembly of car parts being the most familiar example of highly automated systems. Automation has evolved over the decades from the straightforward mechanization of works usually carried out by hand through the introduction of complex automation control systems, and to the extensive 
automation of data collection [7, 8].

According to research that was done on modern labor processes, it suggests that automation displaces and does not replace people and their skills, to planning, distribution, maintenance and additional work. Robotics can be classified as a synchronized process where there is a combination of software, mechanical and electrical engineering [9]. It aims to better the lives of humans who are at risk of getting injured while performing tasks on site. These machines are utilized in the industry to achieve tasks that are in a hazardous location or are repetitive in nature, and as computers are developed, robots are used for increasingly more complex tasks.

There are general lessons that need to be learnt from the manufacturing and construction industry regarding the use of robotics/automation [5, 8, 10], and that is most robotic devices must be considered as an integral part of the design and production process. The reason for this is because the equipment won't be confined to the construction operation alone, but extends through the planning, product design and development of the corporate strategy. Most importantly, flexible automation should be considered from the outset prior to introducing robotics to the construction site itself. Using robotics will have an influence not only on the methods and the process of construction but also the design of the building and the planning and the organization of the construction process [4].

The construction output in some developing countries has grown particularly fast in the recent years, so much so that the growth is often more than the growth rate of the economy, as these countries put their infrastructure in place during the early stages of development. Other countries double their construction outputs and development, therefore creating a rapidly developing industry that needs efficient and innovative solutions to increase the production and quality of work.

Due to the rapid growth of infrastructure and development in the developed countries, many of these developed countries have shifted from the traditional construction procedures to manufacturing prefabricated components in workshops and then they assembled on site [7].

\section{Research Methodology}

Survey design was adopted for this study through the distribution of questionnaire to construction professionals working with construction and consulting firms in Gauteng region of South Africa. These include project managers, quantity surveyors, architects and construction managers. Purposive sampling was adopted by ensuring that respondents have adequate knowledge of automation and robotics as well as good knowledge of the construction industry.

The questionnaire was designed in two parts: the first address necessary background information while the main part was designed to obtain information from respondents on the negative influence of automation on the construction industry. Identified influences from literature were highlighted in a table and 5-point Likert scale was adopted to seek the opinions of respondents. Cronbach alpha value of 0.832 computed for the nine identified factors indicate that the adopted instrument and scale were satisfactory in measuring the opinions of respondents. Mean item score (MIS) and standard deviation (SD) were further calculated for each of the identified variables based on the adopted Likert scale, this was used to rank and determine the level of importance of the factors.

\section{Findings and Discussions}

Fig. 1 shows the type of organization of respondents for the study. Results revealed that of the 40 respondents; $43 \%$ worked for contractors, $18 \%$ worked for project management firms, $13 \%$ worked for quantity surveying firms, $18 \%$ worked for the government, while $10 \%$ worked for architectural firms. 


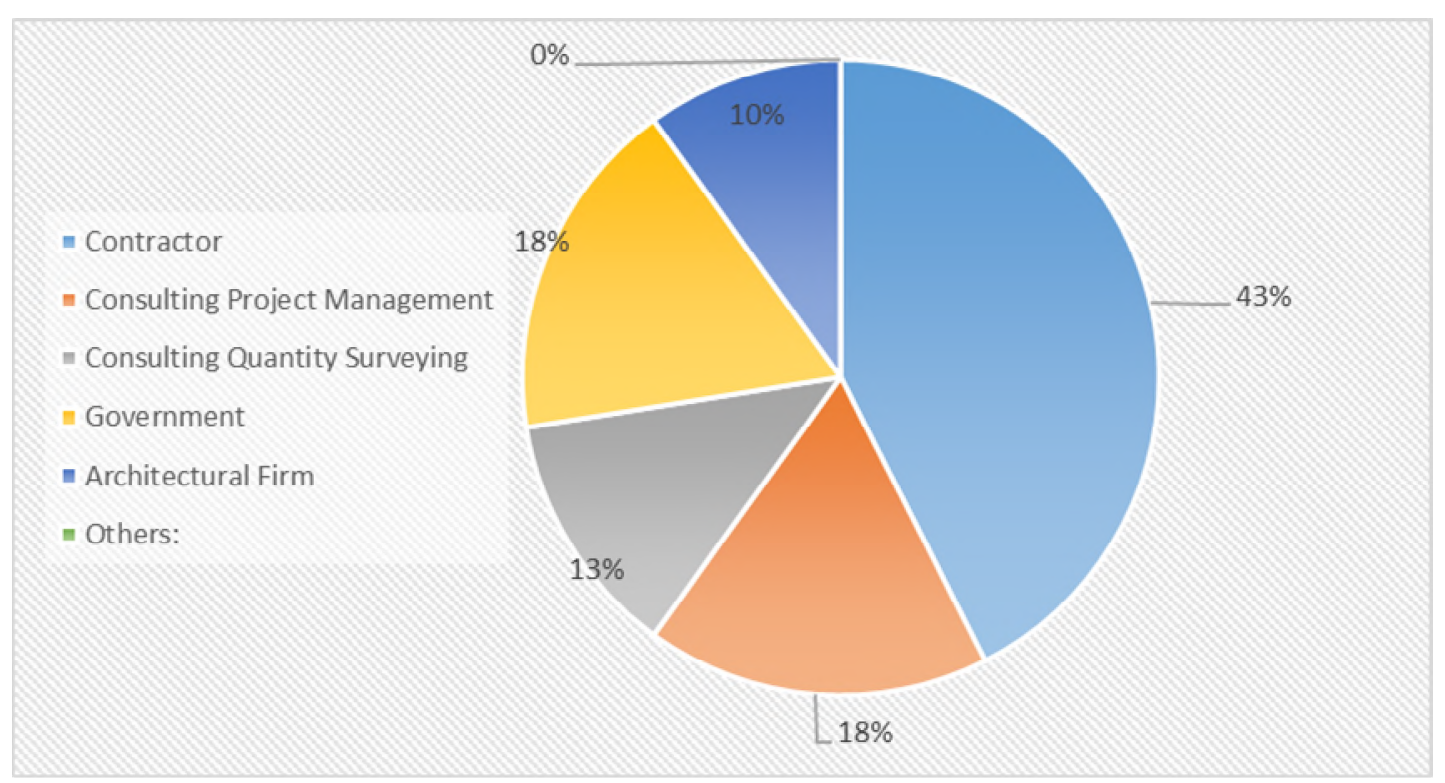

Fig. 1 Type of organization of respondents.

Table 1 shows the opinions of contractors, professionals and their overall views on the negative effects of construction automation in the South African construction industry. Using a 5-point Likert scale of Strongly Disagree- Strong Agree, the respondents were asked to which extent they thought these factors of CA have an effect on the South African construction industry. Results from the contractors show that the top ranked factors were causing worker displacement (MIS=4.00, $\mathrm{SD}=0.791, \mathrm{R}=1$ ), a higher level of maintenance ( $\mathrm{MIS}=3.94, \mathrm{SD}=1.029, \mathrm{R}=2$ ), creating emotional stress of workers (MIS=3.76, $\mathrm{SD}=1.033, \mathrm{R}=3$ ), a lower degree of flexibility (MIS=3.59, $\mathrm{SD}=0.870$, $\mathrm{R}=4$ ) and causing geographical displacement of workers (MIS=3.59, $\mathrm{SD}=0.939, \mathrm{R}=4$ ). Results that were seen as the least effect were the fact that workers becoming slaves to automated machines (MIS=2.88, SD=1.054, R=7) and decrease in productivity/efficiency (MIS=2.76, SD=1.147, $\mathrm{R}=8$ ). From the construction professionals perspective, the dominant negative influence of construction automation include high capital expenditures $(\mathrm{MIS}=3.39, \mathrm{SD}=0.722, \mathrm{R}=1$ ), creating emotional stress of workers (MIS=3.30, $\mathrm{SD}=0.635, \mathrm{R}=2$ ), causing geographical displacement of workers ( $M I S=3.26, S D=0.689, \mathrm{R}=3$ ), causing worker displacement $(\mathrm{MIS}=3.17, \mathrm{SD}=0.576, \mathrm{R}=4$ ) and higher level of maintenance (MIS=3.09, $\mathrm{SD}=0.848, \mathrm{R}=5$ ). Factors with the least dominant effect according to the professionals were employee dissatisfaction ( $\mathrm{MIS}=2.96, \mathrm{SD}=1.022, \mathrm{R}=7$ ) and workers becoming slaves to automated machines (MIS=2.74, $\mathrm{SD}=0.915, \mathrm{R}=8$ ).

Table 1. Disadvantages of automation in the construction industry.

\begin{tabular}{|l|c|c|c|c|c|c|c|c|c|}
\hline \multirow{2}{*}{\multicolumn{1}{|c|}{ Effects }} & \multicolumn{3}{c|}{ Contractors } & \multicolumn{3}{c|}{ Professionals } & \multicolumn{3}{c|}{ Overall } \\
\cline { 2 - 10 } & MIS & SD & R & MIS & SD & R & MIS & SD & R \\
\hline Causing worker displacement & 4.00 & 0.791 & 1 & 3.39 & 0.722 & 1 & 3.53 & 0.784 & 1 \\
\hline Creating emotional stress of workers & 3.94 & 1.029 & 2 & 3.30 & 0.635 & 2 & 3.50 & 0.847 & 2 \\
\hline Higher level of maintenance & 3.76 & 1.033 & 3 & 3.26 & 0.689 & 3 & 3.45 & 1.011 & 3 \\
\hline High capital expenditures & 3.59 & 0.870 & 4 & 3.17 & 0.576 & 4 & 3.43 & 0.781 & 4 \\
\hline Causing geographical displacement of workers & 3.59 & 0.939 & 4 & 3.09 & 0.848 & 5 & 3.40 & 0.810 & 5 \\
\hline Lower degree of flexibility & 3.47 & 0.874 & 6 & 3.00 & 0.798 & 6 & 3.25 & 0.870 & 6 \\
\hline Employee dissatisfaction & 3.35 & 0.115 & 7 & 3.00 & 0.739 & 7 & 3.13 & 1.067 & 7 \\
\hline Decrease in productivity/efficiency & 2.88 & 1.054 & 8 & 2.96 & 1.022 & 8 & 2.90 & 0.928 & 8 \\
\hline Workers becoming slaves to automated machines & 2.76 & 1.147 & 9 & 2.74 & 0.915 & 9 & 2.80 & 0.966 & 9 \\
\hline
\end{tabular}


From the overall findings, the impacts of construction automation include worker displacement (MIS=3.53, $\mathrm{SD}=0.784, \mathrm{R}=1$ ), that it creates emotional stress on workers (MIS=3.50, $\mathrm{SD}=0.847$, $\mathrm{R}=2$ ) and that it has a higher level of maintenance (MIS=3.45, $\mathrm{SD}=1.011, \mathrm{R}=1$ ) were ranked amongst the top three impacts of CA in the South African construction industry. Furthermore, decrease in productivity/efficiency ( $\mathrm{MIS}=2.90, \mathrm{SD}=0.928, \mathrm{R}=8$ ) and workers becoming slaves to automated machines (MIS=2.80, $\mathrm{SD}=0.966, \mathrm{R}=9$ ) were ranked as the least effects/disadvantages of $\mathrm{CA}$ in the South African construction industry.

Based on the ranking using the calculated MIS and the SD for the listed effects/disadvantages of $\mathrm{CA}$ on the South African construction industry, the study revealed that; causing worker displacement, creating emotional stress of workers, higher level of maintenance, and high capital expenditures are the most dominant. The findings are in agreement with existing studies on the fact that automation causes worker displacement and emotional stress of workers [3, 8, 11]. Factors which have the least impact were the decrease in productivity/efficiency and the fact that workers becoming slaves to automated machines.

As much as the adaptation of construction might have various advantages $[2,4,5]$, it also has disadvantages which might in turn affect the productivity of a construction. Findings revealed that construction automation may cause worker displacement or create emotional stress of workers who might feel threatened by the introduction of construction automation. This might have negative implications on construction project delivery or the South African construction industry.

\section{Conclusion and Recommendation}

The findings show that the dominant disadvantages in order of extremity of CA in the South African construction industry are: causing worker displacement, creating emotional stress of workers, higher level of maintenance, high capital expenditures, causing geographical displacement of workers, lower degree of flexibility, employee dissatisfaction, decrease in productivity/efficiency and workers becoming slaves to automated machines.

Furthermore, the findings on the comparisons of the contractors and professional show that the contractor ranked the top five effects as: causing worker displacement, higher level of maintenance, creating emotional stress of workers, lower degree of flexibility and causing geographical displacement of workers. Contractors viewed these effects as the least to have an impact, workers becoming slaves to automated machines and decrease in productivity. Professionals ranked the top five effects as high capital expenditures, creating emotional stress of workers, causing geographical displacement of workers, causing worker displacement and a higher level of maintenance. The least effects were employee dissatisfaction and workers becoming slaves to automated machines.

\section{References}

[1] E. Cottle, The Transformation of the Construction Sector in South Africa since apartheid: Social inequality and labour, Unpublished thesis. Brazil: State University of Campinas, 2014.

[2] Z. Struková, M. Líška, Application of automation and robotics in construction work execution, AD ALTA: J. Interdiscipl. Res. 2(2) (2012) 121-125.

[3] S. Elattar, Automation and Robotics in Construction: Opportunities and challenges, Emirates J. Eng. Res. 13(2) (2008) 21-26.

[4] M. J. Kim, H. Chi, X. Wang, L. Ding, Automation and Robotics in Construction and Civil Engineering, J. Intell. Robot. Syst. 79(3-4) (2015) 347-350.

[5] P. Vähä, T. Heikkilä, P. Kilpeläinen, Extending Automation of Building construction - Survey on potential sensor technologies and robotic applications, Automat. Constr. 36 (2013) 168-178.

[6] P. S. Mistri, H. A. Rathod, Remedies over Barriers of Automation and Robotics for Construction Industry, Int. J. Adv. Res. Eng. Sci. Manag. (2015) 1-4. 
[7] R. Mahbub, Readiness of a Developing Nation in Implementing Automation and Robotics Technologies in Construction: A case study of Malaysia, J. Civil Eng. Archit. 6(7) (2012) 858-866.

[8] A. S. Tambi, A. R. Kolhe, U. Saharkar, Remedies over the Obstacles in Implementing Automation in Indian Infrastructure Projects, Int. J. Res. Eng. Tech. (IJRET) 3(05) (2014) 606-608.

[9] A. Ruggiero, S. Salvo, C. St. Laurent, Robotics in construction, Worcester Polytechnic Institute, 2016.

[10]M. Cusack, Automation and Robotics the Interdependence of Design and Construction Systems, Ind. Robot: Int. J. 21(4) (1994) 10-14.

[11]S. J. Momin, J. R. Patil, R. R. Nale, Enhancement of Road Construction Sector using Automation, Int. Res. J. Eng. Tech. 02(03) (2015) 978-983. 